\title{
A DECISION THEORETIC FRAMEWORK FOR INFORMATION SYSTEM PLANNING IN THE CONSTRUCTION INDUSTRY
}

\author{
Myshkin Ingawale \\ Doctoral Student, Management Information Systems, \\ Indian Institute of Management, Calcutta, India \\ myshkinonline@gmail.com
}

\begin{abstract}
Automation and Information Systems (IS) implementation in the construction industry have evolved in scope and scale of effects over the years. With their growing importance, there is a need for a more practical IS planning approach. Along with the alignment of Information Technology Strategy with the overall corporate strategy of the firm, the Critical Success Factor method, the Value Chain method and other Opportunity frameworks emphasize the prioritization of the key processes for Information Systems planning. The effects of information technology on organizational hierarchy, internal power structures and control flows have been well documented. In the specifics pertaining to the construction industry, this involves a considerably risky transition from a multilevel hierarchy organizational structure to a relatively decentralized, flat organization. This paper presents a decision theoretic framework for Information Systems planning in the construction industry. The objective is to provide a comprehensive and unified approach for analysis and evaluation of the roles, scale and scope of Information Technology in the construction firm. This presupposes elicitation of requirements from a diverse set of stakeholders managers, workers, suppliers and so on. One common problem is the difficulty in maintaining a sufficient degree of formalization and uniformity of structure to ensure effective communication across distributed design teams, while also ensuring adaptability and flexibility in the approach to accurately capture requirements elicitations of different users. The Cognitive Dimensions framework is an approach to analyzing the usability of information artifacts: Here, we apply it to the requirements elicitation process for IS planning in the Construction Industry.
\end{abstract}

\section{KEYWORDS}

IS Planning, Cognitive Dimensions, Requirements Engineering, Human-Centered Systems

\section{INTRODUCTION}

Information system (IS) success is dependent upon the effectiveness of requirements elicitation. A significant portion of IS development failures are attributed to incomplete and inaccurate information requirements $[12,13,14,15,16,17$, $18,19]$. Some studies [5], suggest that as many $90 \%$ of large software projects that fail, owe their failure to the difficulties encountered in accurately capturing system requirements. Incomplete or inaccurate requirements also result in major post-implementation revisions [18] that account for a significant portion of the maintenance costs of IS $[20,21,22]$. The cost of correcting post-implementation problems is considerably higher than that of making changes earlier in the development process [24, 23, 22]. Thus, research that identifies methods for improving the completeness and accuracy of requirements obtained during the requirements elicitation process can provide significant benefits to IS planning efforts. Software support tools have been developed to support all processes of software development, including requirements engineering. However, one area of requirements engineering where support is currently very limited is the area of elicitation. 
This is a difficult area to support because of the wide range of stakeholders who may be involved in the process, the different notations and vocabularies used by these stakeholders and the incompleteness of the requirements at this stage. There is therefore some scope for managing unstructured information during the elicitation process [3]. From past work in this field, there is evidence that more than "hard" studies that yield improvements in implementation phases, the outcomes of the requirements engineering processes can be improved significantly by improving the cognitive strategies of systems analysts $[14,25,26,27,28]$. Research in this area has examined cognitive processes that impacts analysts' ability to obtain complete and accurate requirements [29]. There is also some work on Cognitive Mapping Techniques and Causal, Semantic and Concept mapping have been explored [31], as well as Activity Theory [32]. The gap we see in the existing literature is for a formal methodology to evaluate the cognitive processes of the user and the requirements team on a common platform. Such an approach is especially promising for the construction industry, where the range of user profiles is very diverse, and the processes users follow are the root cause of information intensity in the system, rather than the end product.

The framework we propose in this paper is aimed at overcoming the cognitive limitations that lead to improper elicitation process design. Our Cognitive Dimensions Framework is aimed at ensuring that the primary task of requirements elicitation - that of translating user needs to requirements, is met.

\section{CHALLENGES IN REQUIREMENTS ELICITATION}

As per [30], Requirements Elicitation implies learning, uncovering, extracting, surfacing, or discovering needs of customers, users, and other potential stakeholders in the System to be developed. Requirements engineering processes are dominated by human, social and organizational factors because they involve a range of stakeholders from different backgrounds and with different individual and organizational goals [2]. Common requirements problems which arise [2] are

- The requirements don't reflect the real needs of the customers of the system

- The requirements are inconsistent and/or incomplete

- It is expensive to make changes to requirements after they have been agreed

- There are misunderstandings between customers, those developing the system requirements and software engineers developing or maintaining the system

Requirements elicitation is constrained by not only the user-side problems stated above but also the cognitive limitations of analysts, as per [1].

\section{USABILITY OF THE ELICITATION PROCESS}

The concept of usability as applied to software with graphical user interfaces (GUIs) - developer tools, word processors, or e-mail clients, is well understood. We expect these tools to let us perform a given set of tasks and to work the way we expect them to. If any of the products that we use fail to work in the way that we expect them to, we generally label this as poor design or usability [7]. There can be many causes for poor product usability or design; for example, users may not be aware of the actions that they can take with a product. Likewise, they may not be able to predict the result of performing some action and hence might be reluctant or less inclined to perform that action for fear of the potentially negative consequences that might ensue. Or they misinterpret the actions that they can take and the results of those actions. It is worthwhile to develop the concept of usability as applicable to the product of the requirements elicitation process of information systems projects in the construction industry, as the objective here too is to minimize misinterpretations both from the users and the requirements team, ensure active participation and maximize predictability of actions for the users. 


\section{RATIONALE FOR CHOICE OF CD FRAMEWORK}

Cognitive engineering offers a principled approach to the design and development of human-centered systems. The cognitive engineering process integrates an analysis of the cognitive and collaborative demands of a user engaged in work with an iterative design, implementation, and evaluation approach to developing support tools [4]. The cognitive dimensions framework has evolved from research done at Cambridge University, UK on programming language usability. In this paper, we draw the analogy between the programmer in the case of an API and the end user in the case of software being developed. We contend that the layers of abstraction that the API presents to the programmer to access the functionality of the programming language are of a similar nature to the layers of abstraction that software presents to the end user to access the functionality of the underlying processes, and therefore, the theories of usability that are applicable in the context of API can be fruitfully extended to requirements elicitation. The cognitive dimensions we have chosen here have been developed for the representation of notations such as music and Morse [9] and have also been successfully applied for API usability studies [7].

\section{COGNITIVE DIMENSIONS}

The cognitive dimensions framework presents a set of 12 different dimensions (or factors) that individually and collectively have an impact on the way that users interact with the requirements elicitation process and on the way that users expect the requirements to be translated into a working system. These dimensions are as follows:

\section{Abstraction Level}

They specify the minimum and maximum levels of abstraction exposed to the user, and are a measure of the type and number of abstractions that the user has to contend with. These types are primitives, factored or aggregate.

\section{Learning style}

The learning requirements posed by system, and the learning styles comfortable for a targeted user, in the context of the given system.

\section{Working framework}

The size of the conceptual chunk (user working set) needed to work effectively. It specifies the context that users need to maintain when working with a process.

\section{Work-step unit}

It specifies the magnitude of the task that must/can be completed in a single step.

\section{Progressive evaluation}

It describes the extent to which partially completed description can be utilized to obtain feedback on system design.

\section{Premature commitment}

This factor measures the amount of decisions that users have to make when using the system, and the consequences of those decisions.

\section{Penetrability}

Penetrability defines the extent to which the requirements process facilitates exploration, analysis, and understanding of the overall system components, and how targeted users go about relating and retrieving what is needed.

\section{Elaboration}

Elaboration is a measure of the extent to which the system components must be adapted to meet the needs of targeted users.

\section{Viscosity}

This is a measure of the barriers to change inherent in the system process and how much effort a targeted user needs to expend to make a change.

\section{Consistency}

This indicates the extent to which the rest of the tasks in the system can be inferred once part of it is finalized.

\section{Role expressiveness}

This measures the apparentness of the relationship between each component exposed by the requirements process and the system as a whole. 


\section{Domain correspondence}

This is a measure of how clearly the system components map to the domain and any special tricks that the user needs to be aware of to request some functionality. User's domain models will not necessarily be the same as requirement team's.

\section{RELEVANCE TO THE CONSTRUCTION INDUSTRY}

A principal characteristic of construction industry projects is the distributed nature of the project team. The industry is generally regarded as relatively inefficient when compared to other sectors such as manufacturing and electronics [35]. Inefficiencies arise in the construction industry because the fragmented groups have difficulty coordinating their efforts and combining their individual contributions [33]. The industry is characterized as being fragmental in participants and processes. Participants of the industry range from large international enterprises to small local businesses all with various capabilities and interests. Multiple parties are involved in the industry business activities, such as owners, designers, contractors, suppliers, manufacturers, and supporting service providers. The process is considered as fragmented due to the participation of different parties at different stages in the construction process (design, procure, construct, and operate), as well as many specialized systems of components (structural, electrical, mechanical, etc.) that make up the final product. Due to the number of participants involved, the complexity of the product, and the short term of execution, the volume of information flowing through the construction processes is extensive and complex [34]. Given these factors, it is unlikely that one common system design would map to the mental models of tasks of all the stakeholders. With the Cognitive Dimensions Framework applied iteratively to each unit of the system design independently of the requirements elicitation process, this mismatch can be reduced.

\section{PROCESS FLOW}

The following section explains the process to measure and apply these 12 cognitive dimensions in the context of the requirements process. We use as an example the cognitive dimensions framework applied to a Systems Requirements study for IS planning at Dwaraka Constructions, a medium sized Road construction firm with operations in Kadapa District, Andhra Pradesh, India. The firm is responsible for laying and maintaining various road projects across Kadapa district. The operations of the organization revolve around Material, Machine and employees/labourers. While the specifics of the firm or the system need not concern us, the methodology of application of the CD framework is illustrated here.

The process flow is thus: First, the study is initiated after a request for proposal. The business processes of the firm are analyzed, and the stakeholders in the new system identified as being Top Management, Resource Managers, Machines-In-charge, Plant Managers and Financial Managers. The Requirements Elicitation process consists of identifying, formalizing and documenting the requirements of these diverse user groups. The end-product is a set of Requirements Specifications Documents (Process Flow, Functional Specifications and Database Structure Documents). Now, we apply the CD framework to the proposed system and to the personas of the stakeholders, independently.

\subsection{Scores for the Proposed System}

The System (as specified in the Requirements Specifications Document) is subdivided into modules, on the basis of user group. Here, the modules would be areas of the system to be used by the top management, those used by the resource managers, and so on. Each module is evaluated along the 12 dimensions on a scale of 1-4. The scores of each module for the CD parameters are noted. This is a subjective assessment, performed by the system designers.

\subsection{Scores for the User Groups}

The user groups identified at the requirements elicitation phase are now separately studied to evaluate their scores along the 12 cognitive dimensions. Again, this is a subjective assessment, performed with inputs from the top management. Within each user group, each user 
will have a unique set of $\mathrm{CD}$ scores. For the present example, we have taken a 'representative user' of each user group

\subsection{Radar}

The CD Radar for each module consists of 2 graphs: The plot of the CD scores for the System and those for the User Groups. It is a convenient visualization tool to understand the gaps between the actual user requirements and the proposed system design. Figure 1 shows the CD Radar for PM_Module - The project management module which will be used by the resource managers.

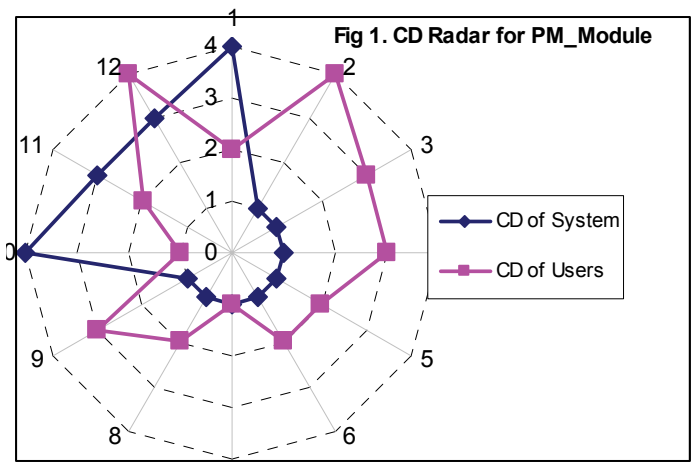

Figure 1 CD Radar for PM_Module

Table 1 CD Scores for PM_Module

\begin{tabular}{|l|l|l|}
\hline CD no. & System & Users \\
\hline 1 & 4 & 2 \\
\hline 2 & 1 & 4 \\
\hline 3 & 1 & 3 \\
\hline 4 & 1 & 3 \\
\hline 5 & 1 & 2 \\
\hline 6 & 1 & 2 \\
\hline 7 & 1 & 1 \\
\hline 8 & 1 & 2 \\
\hline 9 & 1 & 3 \\
\hline 10 & 4 & 1 \\
\hline 11 & 3 & 2 \\
\hline 12 & 3 & 4 \\
\hline
\end{tabular}

The closeness of fit between the two curves is a measure of the degree of match between the user's actual requirements and the proposed system design. For instance, in Table 1, for Cognitive Dimension 4 - Work Step Unit, the System scored 1 and the User Group (Resource
Managers) scored 3. This implies that the magnitude of task that the PM_Module would typically perform at one step is much lower than the level at which the users are most comfortable at. A corrective measure would be to revise this aspect of the system design. If the gap for any CD parameter deemed critical is beyond the tolerance levels, then the system design may be modified by modifying the elicitation process itself and performing the requirements phase again. This is an iterative process.

\subsection{Using Personas}

It may not be easy to figure out the right adjustment for gaps, to the requirements process, since user groups are not homogeneous. We use personas to represent our understanding of who our users are, and then plot the CD Radar for the 'representative persona' of each user group. Using the API Usability Study's [7] definitions of three main user profiles we describe the stereotypical behavior of three main user group types: Opportunistic, Pragmatic and Systematic. The rationale for fitting these user types from software development to the construction industry is that this is a fairly generic classification, and is based on the cognitive processes users follow to do a task, rather than the task itself. Table 2 gives the preferences of cognitive dimensions by the different persona types. Representative Personas for each user group, once found- systematic, pragmatic and opportunistic - will in turn drive the system design and next iteration of requirements elicitation.

\section{CONCLUSION}

To ensure that we know how users expect requirements to translate to a working system, designing the requirements elicitation process through human-centered design is a starting point. We can use the cognitive dimensions framework to describe how well the process meets our users' requirements and to gather feedback from users. The CD framework enables a closer match between information requirements gathered by the requirements team and the actual user needs and provides a platform with which to 
Table 2 CD Preferences by User Type

\begin{tabular}{|c|c|c|c|}
\hline \multicolumn{4}{|c|}{ User Type Preference } \\
\hline Dimensions & Systematic & Pragmatic & Opportunistic \\
\hline Abstraction Level & $\begin{array}{l}\text { Prefer Primitives } \\
\text { Tolerate Aggregates } \\
\end{array}$ & $\begin{array}{l}\text { Prefer Aggregates } \\
\text { Can't tolerate Factored }\end{array}$ & Prefer Aggregates \\
\hline Learning Style & Top-Down & Stepwise & Minimal Incremental \\
\hline Working Framework & System, Reengineered & Global & Local \\
\hline Work-Step Unit & Abstraction Dependent & Functional Incremental & Local Incremental \\
\hline Progressive Evaluation & $\begin{array}{l}\text { High Frequency } \\
\text { Abstraction Dependent }\end{array}$ & $\begin{array}{l}\text { Low to Medium } \\
\text { Frequency Tolerated }\end{array}$ & Undesirable \\
\hline Premature Commitment & Prefer Low & Prefer Low & Prefer Low \\
\hline Penetrability & $\begin{array}{l}\text { Expansive } \\
\text { Extensive }\end{array}$ & Context Driven & Snapshot \\
\hline Elaboration & High Control & Fine Tune & Ready use \\
\hline Viscosity & $\begin{array}{l}\text { Low } \\
\text { High if High Control }\end{array}$ & Low & Low \\
\hline Consistency & High & High & High \\
\hline Role Expressiveness & $\begin{array}{l}\text { Prefer Transparent } \\
\text { Tolerate Opaque }\end{array}$ & $\begin{array}{l}\text { Prefer Transparent } \\
\text { Tolerate Plausible }\end{array}$ & Transparent \\
\hline $\begin{array}{l}\text { Domain } \\
\text { Correspondence }\end{array}$ & $\begin{array}{l}\text { Prefer Direct } \\
\text { Tolerate Arbitrary }\end{array}$ & $\begin{array}{l}\text { Prefer Direct } \\
\text { Tolerate Plausible }\end{array}$ & Direct \\
\hline
\end{tabular}

understand the results of the analysis. It helps understand causes, not symptoms and enables the user-centered approach for requirements engineering. Effective requirements elicitation depends upon the ability of users and analysts to understand and appreciate one another's worlds: The CD framework provides a common language to foster this understanding.

\section{REFERENCES}

[1] Pitts, Mitzi G, Browne and Glenn J, Improving requirements elicitation: an empirical investigation of procedural prompts, Information Systems Journal, Jan2007, Vol. 17 Issue 1, p89-110

[2] Gerald Kotonya, Ian Sommerville, Requirements Engineering: Processes and Techniques, John Wiley \& Sons , 1998-08-24 ISBN: 0471972088
[3] I. Sommerville and T. Rodden, Human, social and organisational influences on the software processes, Software Process, Vol. 4 of Trends in Software (A. Fuggetta and A. Wolf, eds.), J. Wiley, 1996.

[4] Pfautz J., Roth E., Using cognitive engineering for system design and evaluation: A visualization aid for stability and support operations, International Journal of Industrial Ergonomics, May2006, Vol. 36 Issue 5, p389407

[5] Valusek, J. and D. Fryback, "Information Requirements Elicitation: Obstacles Within. Among, and Between Participants", Galtiers. (Ed.). Information Analysis: Selected Readings. MA: Addison-Wesley, 1992, pp. 139-151. 
[6] Davis, Tremplay, Fuller and Berndt, Communication Challenges in Requirements Elicitation and the Use of the Repertory Grid Technique, Journal of Computer Information Systems, Special Issue 2006

[7] Steven Clarke, Measuring API Usability, Dr. Dobb's Journal Windows/.NET Supplement, May 2004

[8] Green, T. R. G., Instructions and descriptions: some cognitive aspects of programming and similar activities, Proceedings of Working Conference on Advanced Visual Interfaces, 2000, New York: ACM Press, pp 21-28.

[9] Blackwell, A. F. and Green, T. R. G., Notational systems of the Cognitive Dimensions of Notations framework. In John M. Carroll (Ed.) HCI Models, Theories and Frameworks, 2003, cha 5, pp 103-133. Amsterdam etc: Morgan Kaufmann.

[10] Blackwell, A.F. \& Green, T.R.G., A Cognitive Dimensions questionnaire optimised for users, In A.F. Blackwell \& E. Bilotta (Eds.) Proceedings of the Twelth Annual Meeting of the Psychology of Programming Interest Group, 2000, 137-152.

[11] Pitts, Mitzi G. and Glenn J. Browne. Stopping Behavior of Systems Analysts During Information Requirements Elicitation, Journal of Management Information Systems, 21, 2004, pp. 203-226.

[12] Bostrom R.P., Successful application of communication techniques to improve the systems development process, Information \& Management, 16, 5 (1989), 279-295.

[13] Byrd T.A., Cossick K.L., and Zmud R.W., A synthesis of research on requirements analysis and knowledge acquisition techniques, MIS Quarterly, 16, 1 (1992), 117-138.

[14] Davis G.B., Strategies for information requirements determination, IBM Systems Journal, 21, 1 (1982), 4-30.

[15] The Chaos Report, Standish Group International, Inc, West Yarmouth, MA, 1995.
[16] Vessey I., and Conger S., Learning to specify information requirements: The relationship between application and methodology, Journal of Management Information Systems, 10, 2 (Fall 1993), 177-201.

[17] Watson H.J., and Frolick M.N., Determining information requirements for an EIS, MIS Quarterly, 17, 3 (September 1993), 255-269.

[18] Wetherbe J.C., Executive information requirements: Getting it right, MIS Quarterly, 15,1 (March 1991), 51-65.

[19] Whitten J.L., Bentley L.D., and Barlow V.M, Systems Analysis and Design Methods, 4th edition. Burr Ridge, IL: Irwin, 1998.

[20] Lientz B.P., and Swanson E.B., Software Maintenance Management, Reading, MA:Addison-Wesley, 1980.

[21] Ramamoorthy C.V., Prakash A., Tsai W., and Usuda Y., Software engineering: Problems and perspectives, Computer, 17, 10 (1984), 191209.

[22] Shemer I., A systemic analysis of a conceptual model, Communications of the ACM, 30, 6 (1987), 506-512.

[23] Robertson, S., and Robertson, J, Mastering the Requirements Process, Harlow, UK: AddisonWesley, 1999.

[24] Boehm, B.W, Software Engineering Economics, Englewood Cliffs, NJ: Prentice Hall, 1981.

[25] Leifer R., Lee S. and Durgee J., Deep structures: Real information requirements determination, Information and Management, 27, 5 (1994), 275-285.

[26] Valusek, J.R., and Fryback, D.G, Information requirements determination: Obstacles ithin, among and between participants, R. Galliers (ed.), Information Analysis: Selected readings. Reading, MA: Addison-Wesley, 1987.

[27] Walz, D.B.; Elam, J.J.; and Curtis, B, Inside a software design team: Knowledge acquisition, sharing, and integration, Communications of the ACM, 36, 10 (1993), 63-77. 
[28] Zmud, R.W., Anthony, W.P., and Stair, R.M., Jr. The use of mental imagery to facilitate information identification in requirements analysis, Journal of Management Information Systems, 9, 4 (Spring 1993), 175-191.

[29] Pitts, Mitzi G. and Glenn J. Browne. Stopping Behavior of Systems Analysts During Information Requirements Elicitation, Journal of Management Information Systems, 21, 2004, pp. 203-226.

[30] Hickey A., Davis A., A Unified Model of Requirements Elicitation, Journal of Management Information Systems / Spring 2004, Vol. 20, No. 4, pp. 65-84.

[31] Siau K., Tan X., Using Cognitive Mapping Techniques to Supplement UML and UP in Information Requirements Determination, Journal of Computer Information Systems, Special Issue 2006
[32] Martins L., Daltrini B., An Approach to Software Requirements Elicitation Using the Precepts from Activity Theory, 14th IEEE International Conference on Automated Software Engineering, 1999, p. 15

[33] Paulson BC., International Constructioncooperation and collaboration in a world of contracts, constrains, competition and conflicts, Proceedings of $1^{\text {st }}$ International conference on construction project management, Nanyang Technological University, (1995), Singapore.

[34] Chen Y, Rankin J, ACM International Conference Proceeding Series, Vol. 156, Pages: $411-419,2006$

[35] Howard H. C., Levitt R.E., Paulson, B.C., Pohl, J.G., and Tatum, C.B., Computerintegration: reducing fragmentation in the AEC industry, Journal of computing in civil engineering, 3 (1989), 18-32. 